\title{
Metascience: reflections on the symposium
}

\author{
Luciano Boschiero' ${ }^{1}$ K. Brad Wray ${ }^{2}$
}

Published online: 15 June 2016

(C) Springer Science+Business Media Dordrecht 2016

From antiquity to the late renaissance, a symposium was regarded as a convivial gathering of well-educated individuals to discuss a specific matter intelligently while enjoying wine. The modern meaning of the word, for better or for worse, has dropped the implication of a drinking party and (perhaps as a consequence) does not always elicit conviviality from its participants. Fortunately, opening every print edition of Metascience, we are able to present a symposium that retains the tradition of well-informed, expert discussion. We also like to think that while there may be robust exchanges of opinion, they are always done convivially and respectfully. Furthermore, in keeping with tradition, one can even enjoy reading our symposia with a drink in hand.

In this issue, we present such a symposium based on Steven French's The Structure of the World: Metaphysics and Representation (Oxford, 2014). French responds to the reviews of three colleagues, Mauro Dorato, Elaine Landry and Stathis Psillos. Aside from the insight all four contributors provide into French's defence of ontic structural realism (OSR), this symposium is also interesting for another reason: both French and Psillos are former editors of this journal. So, while they have a strong exchange of views, they also exhibit a respect for each other's work that exemplifies the tone and purpose of our symposia. This is not to ignore Dorato's and Landry's contributions, which are also of exemplary quality.

Aside from this issue's symposium, we are also certain you'll enjoy the many essay reviews and standard-length reviews on offer as we continue to strive for a mix of topics relating to history of science, philosophy of science, and science and technology studies.

Luciano Boschiero

1.boschiero@campion.edu.au

1 Campion College, Sydney, Australia

2 State University of New York, Oswego, Oswego, NY, USA 
We would like to thank the reviewers who have contributed to this issue for the quality of their analyses, as well as the book authors for providing such rich and varied material for the edification of our community of scholars. Thanks also to the publishers who freely provide copies of these works for review, especially Springer for its continued support of this journal and of our conjoined fields of historical, philosophical and sociological enquiry into the sciences. Sadly, Steve O'Reilly has departed the Metascience team at Springer. We would like to wish him well as he continues his work with Springer, and we thank him for his assistance over the past year. Meanwhile, we are thankful for the continued brilliant service from Lucy Fleet and Catherine Murphy, as well as David Lambie, our Assistant Editor, and the members of the Editorial Board, all of whom volunteer their time to ensure we match suitable books to the right reviewers. 